\title{
Rendezvous recanalization of a postoperative coloanal anastomotic dehiscence with a lumen-apposing metal stent
}

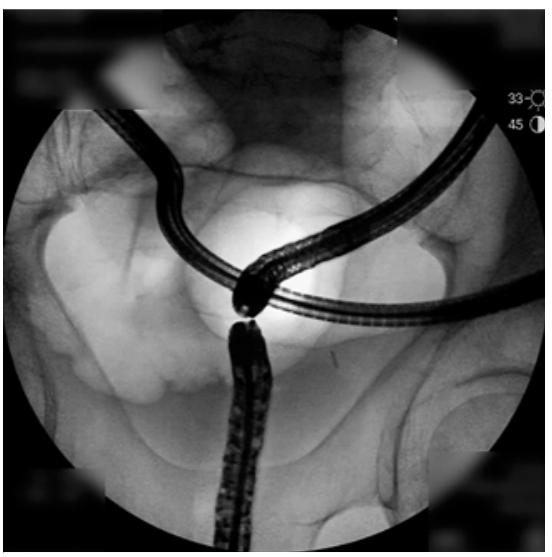

> Fig. 1 Fluoroscopic image showing the rendezvous approach.

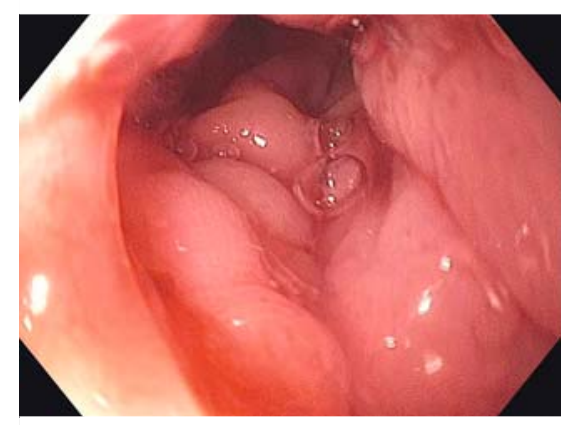

> Fig. 4 Endoscopic view showing the patent anastomosis after stent removal.

LAMSs have been successfully used for the recanalization of complete colorectal anastomotic obstructions [1,2]. However, there are no reports of using LAMSs in the treatment of coloanal anastomotic dehiscence.

A 51-year-old man with a rectosigmoid tumor underwent low anterior resection. His surgery was then complicated by leakage, which was treated by proctectomy, coloanal anastomosis, and creation of a diverting ileostomy. On followup sigmoidoscopy, the anastomosis appeared to have dehisced and no lumen to the proximal colon was identified. Therefore, a rendezvous approach was planned for the treatment of coloanal anastomotic dehiscence.

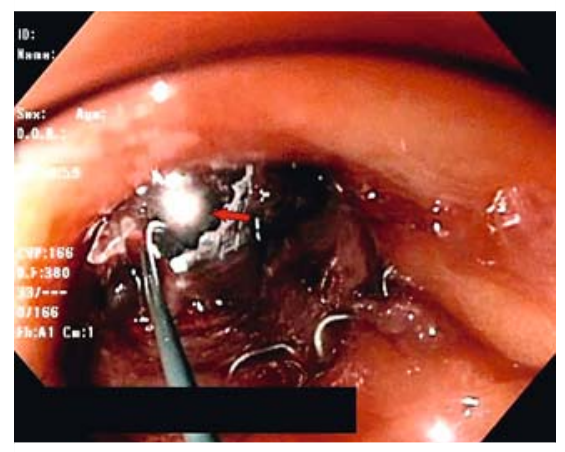

- Fig. 2 Endoscopic view showing proper deployment of the stent across the dehiscence.

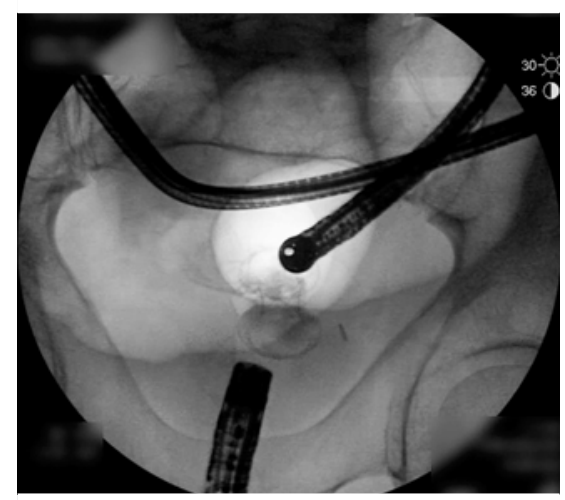

- Fig. 3 Fluoroscopic image showing the lumen-apposing metal stent in situ.

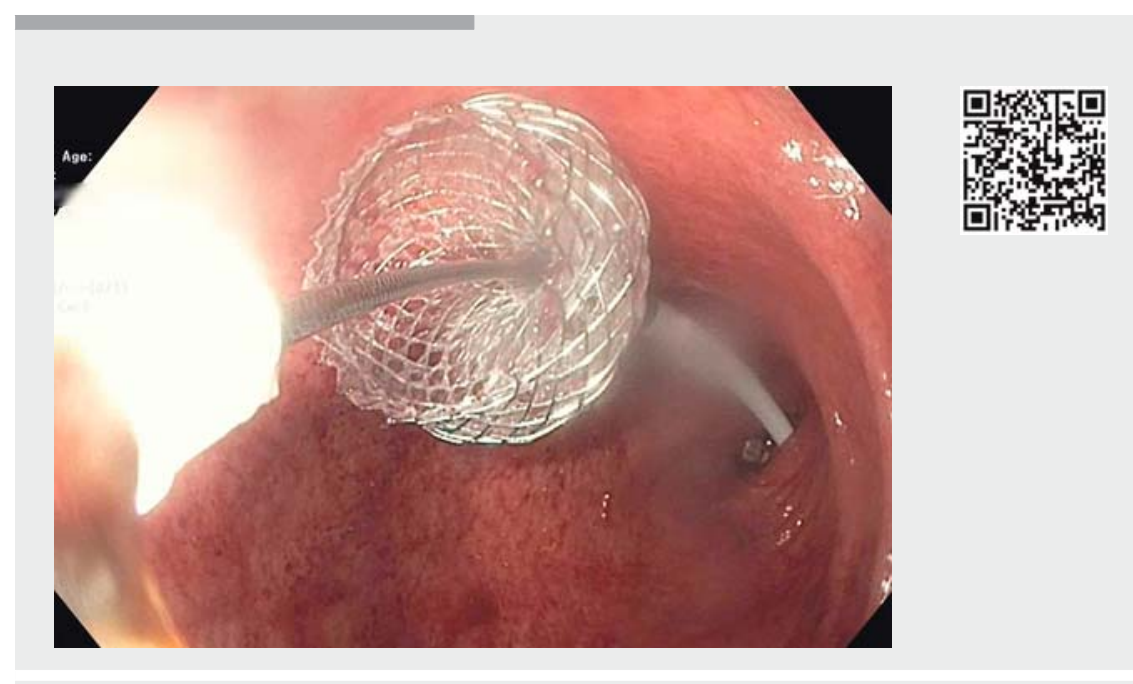

Video 1 The video shows the rendezvous approach being used to recanalize a coloanal anastomotic dehiscence with a lumen-apposing metal stent.

An upper gastrointestinal (GI) endoscope was advanced transanally to the coloanal anastomosis, while a pediatric colonoscope was advanced towards the anastomosis through the loop ileostomy ( Fig.1). With the use of fluoroscopic guidance and transillumination, the dehiscent coloanal anastomosis was identified. A guidewire was advanced in an antegrade direction and was captured from the anus. A $15 \times 10-m m$ LAMS was then inserted over the wire from the anal side and successfully deployed across the anastomosis ( $\mathbf{F i g .} 2$ and - Fig. 3; Video 1 ).

The patient was discharged home in good condition 1 day after the procedure. After 2 months, a flexible sigmoidoscopy was carried out, in which the stent was removed with a forceps. The upper Gl endoscope was advanced to a point proximal to the anastomosis, which was noted to be widely patent ( $>$ Fig. 4 ). The stent was then reloaded into the therapeutic upper 
$G$ endoscope and redeployed across the anastomosis to ensure the area remained patent. After 4 months, the stent was removed following ileostomy reversal. The patient continues to do well after 3 months of follow-up.

In conclusion, treatment of postoperative coloanal anastomotic dehiscence using a LAMS placed via the rendezvous technique is feasible and effective.

Endoscopy_UCTN_Code_TTT_1AQ_2AG

\section{Competing interests}

Mouen A. Khashab is a consultant and on the medical advisory board for Boston Scientific and Olympus. The remaining authors have nothing to disclose.

The authors

Omid Sanaei, Olaya Brewer Gutierrez, Robert Moran, Juliana Yang, Mouen A. Khashab Division of Gastroenterology and Hepatology, Johns Hopkins Medical Institutions, Baltimore, Maryland, USA

\section{Corresponding author}

\section{Mouen A. Khashab, MD}

Johns Hopkins Hospital, 1800 Orleans Street, Sheikh Zayed Tower, Baltimore, MD 21287,

USA

Phone: +1-443-287-1960

mkhasha1@jhmi.edu

\section{References}

[1] Gornals JB, Albines G, Trenti L et al. EUSguided recanalization of a complete rectal anastomotic stenosis by use of a lumenapposing metal stent. Gastrointest Endosc 2017; 82: 752

[2] Sanaei O, Ngamruengphong S, Chen YI et al. Endoscopic ultrasonography-guided freestyle rendezvous recanalization of a complete postoperative rectosigmoid anastomotic obstruction with a lumen-apposing metal stent. Endoscopy 2017; 49: E206E207

\section{Bibliography}

DOI https://doi.org/10.1055/a-0591-2148

Published online: 9.4.2018

Endoscopy 2018; 50: 646-647

(c) Georg Thieme Verlag KG

Stuttgart · New York

ISSN 0013-726X

\section{ENDOSCOPY E-VIDEOS}

https://eref.thieme.de/e-videos

回回 Endoscopy E-Videos is a free access online section, reporting 口. on interesting cases and new techniques in gastroenterological endoscopy. All papers include a high quality video and all contributions are freely accessible online.

This section has its own submission website at

https://mc.manuscriptcentral.com/e-videos

\section{CORRECTION}

Sanaei O, Brewer Gutierrez O, Moran $\mathrm{R}$ et al. Rendezvous recanalization of a postoperative coloanal anastomotic dehiscence with a lumen-apposing metal stent.

Endoscopy 2018, 50:

doi:10.1055/a-0591-2148

In the above mentioned article the page numbers have been corrected. This was corrected in the online version on August 17, 2018. 